\title{
Evaluation Studies of Leisure Agriculture in Hebei Province
}

\author{
SHI Wei-Li \\ Department of Science and Research \\ Hebei University of Science and Technology \\ Shijiazhuang, China \\ swlsjz@hebust.edu.cn
}

\author{
KONG Qing-shu \\ Department of Planning and department \\ Hebei University of Science and Technology \\ Shijiazhuang, China \\ kongqingshu@163.com
}

\begin{abstract}
Leisure agriculture has dual features of agriculture and tourism, and its basic features include the marketability, science \& technology, spectator, experience, culture, education, ecology etc. Leisure agriculture and rural tourism demonstration sites are typical cases who selected out by the Ministry of Agriculture and the National Tourism Administration, and they are demonstrate significance. Taking 10 leisure agriculture and rural tourism demonstration sites of Hebei province in 2011 as the samples, this text does example analysis and measure from comprehensive benefit, economic benefit, social benefit with DEA, in the end it obtains the following conclusions: the overall efficiency of leisure agriculture in Hebei province is low, which should increase investment to seek rapid development; To change the small and fully equipped developmental pattern and confirm the development direction to scale development, especially for experience project. The main body of management needs to improve management level and service quality basis on creating the park technology, and the relevant department \& the main body of management should not only meet with the economic benefits from leisure agriculture improved but also pay attention to raise and push social benefits from local employment.
\end{abstract}

Keywords-Leisureagriculture; tourism ; Demonstration;Hebei province; Evaluation

\section{INTRODUCTION}

It's a major agricultural province in Hebei. There has unique conditions and potential for the development of leisure agriculture and rural tourism, on account of various types and vast rural area, adjacent to Beijing and Tianjin. At present, there are 3 national leisure agriculture and rural tourism demonstration counties, 31 national leisure agriculture and rural tourism demonstration sites, 61 provincial leisure agriculture and rural tourism demonstration sites ${ }^{[1]}$. In this paper, we use the DEA method to study and evaluate leisure agriculture and rural tourism development, aim to standardize and enhance the development of leisure agriculture and rural tourism in Hebei Province, in order to lead the national leisure agriculture and rural tourism industry to keep sustained and healthy development.

\section{CONCEPT OF LEISURE AGRICULTURE AND ITS BASIC FEATURES}

\section{A. The concept of leisure agriculture}

Leisure agriculture originated in Europe, the original word is "Leisure Agriculture" [2]. In domestic, though conceptions of leisure agriculture are not alike, but all are similar meaning. Reference others research-ideas, this study suggests, through the development of the tourism value of agricultural products and services, the leisure agriculture business entities attract people to come to eat, live, watch, experience, purchase, entertainment, education and other activities in the farm to experience the new forms of tourism, in order to taste the agricultural practices and experience the eco-fun.

\section{B. The basic features of leisure agriculture}

Leisure agriculture has the dual properties of agriculture and tourism, It can infer the basic features for marketability, technology, appreciation, experience, culture, education, ecology, etc. The bases of leisure agriculture is viewing the pick of agricultural products and services, the main leisure agriculture offer leisure agriculture experience, people involved in agricultural production, experiencing agricultural production practice, to learn agricultural production technology, access to gain agricultural knowledge and fun culture.

\section{LEISURE AGRICULTURE EVALUATION BASED ON DEA}

DEA is a system analysis method proposed by $\mathrm{A}$. Charnes, W.W.Cooper etc., based on the benefit evaluation on different types of units (departments) with multi-inputs and multi-outputs to evaluate the comparative validity of a couple of homogeneous decision making units for evaluating the relative effectiveness of homogeneous decision making unit (DMU) ${ }^{[3]}$. It's a quantitative analysis method in the evaluation of the relative effectiveness of the comparability of the same type of units ${ }^{[4]}$.

A. Basic model of DEA---C $C^{2} R$ model

$\mathrm{C}^{2} \mathrm{R}$ model is the basic model of DEA. Its optimal planning model is as follows: 


$$
\text { (D) }\left\{\begin{array}{l}
\min \theta=V_{D_{1}} \\
\text { s.t. } \quad \sum_{j=1}^{n} x_{j} \lambda_{j} \leq \theta_{x_{0}}, \\
\sum_{j=1}^{n} y_{j} \lambda_{j} \geq y_{0}, \\
\lambda \geq 0, j=1,2, \cdots, n, \theta \in E^{1}
\end{array}\right.
$$

By adding slack variable $s^{+}$and the remaining variable $s^{-}$, it can be concluded:

$$
\left(D_{1}\right)\left\{\begin{array}{c}
\min \theta=V_{D_{1}} \\
\text { s.t. } \quad \sum_{j=1}^{n} x_{j} \lambda_{j}+s^{+}=\theta_{x_{0}}, \\
\sum_{j=1}^{n} y_{j} \lambda_{j}-s^{-}=y_{0}, \\
\lambda \geq 0, j=1,2, \cdots, n, \\
s^{+} \geq 0 ; s^{-} \geq 0 .
\end{array}\right.
$$

According to the related theories and the definitions, the conclusions are:

1) If $\theta=1$ and $S^{+}=S^{-}=0$, it is observed that the corresponding activities from a technical point of view, the resources can be fully utilized, the input elements achieved the best combination, and the maximum output effect was achieved.

2) If $\theta=1$ and $S^{+}=S^{-} \neq 0, D M U_{j_{0}}$ is called weak DEA efficient, technology and scale are not efficient simultaneously, and at this time economic activities are not the optimal technologic efficiency and the optimal scale income.

3) If $\theta<1$. The decision-making units are neither optimal technical efficiency, nor the scale income.

In addition, the DMU scale is effective if $\sum \lambda=1$, the return to scale increases progressively if $\sum \lambda<1$, and the return to scale decreases progressively if $\sum \lambda>1^{[5]}$.

\section{B. Established evaluation system of leisure agriculture based on DEA.}

Using the Delphi method, requesting for evaluation of the relevant experts, through the form of questionnaires, interviews and repeatedly modify. The final selection is the following evaluation index system in Table 1.

Input indexes, that human, financial and material resources in decision-making units of leisure agriculture.

The human indicator selects the number of main practitioners of technological activities in leisure agriculture, means that development of leisure agriculture needs support of scientific and technological.

Financial indicator selects the project's investment of leisure experience, because the core business of leisure agriculture should be experience business.
Material indicator selects the type of tourism elements in leisure agriculture, seven tourism elements including eating, living, seeing, experiencing, shopping, entertaining, educating, reflect the integrated service capabilities of leisure agriculture sample.

Output indexes, that the output of economic benefits, social benefits in leisure agriculture sample.

The economic efficiency indicator selects annual revenues of indicators of reflect the leisure agriculture business strength.

Social benefit indicator selects the number of local annual employment indicators to promote the farmers to increase.

\section{Analysis and evaluation of leisure agriculture in Hebei Province based on DEA}

10 samples of leisure agriculture are selected in Hebei Province .Using the data in 2011, obtained samples comprehensive technical efficiency, pure technical efficiency and scale efficiency, as well as input redundancy situation, the results can be seen from Table 2 .

\section{EVAluation OF Leisure AgRiculture In HeBeI PROVINCE BASED ON DEA}

Through the DEA analysis, and combined with field investigation and comprehensive expert opinion, etc, we concluded the evaluations of leisure agriculture in hebei province.

\section{A. Overall efficiency of leisure agriculture in Hebei is low,it need to increase investment for rapid development.}

In the 10 leisure agriculture demonstration sites in Hebei Province, only 6 sites are comprehensive technical efficiency, there accounting for $60 \%$ of the total. Above the 10 samples ,as the better demonstration sites of Hebei Province, the analysis shows that the overall efficiency of Hebei is low, it need to increase business investment to achieve the best efficiency of the total output.

B. All-round development of leisure agriculture in hebei province is to lack of stamina, the direction of leisure agriculture is scale development in Hebei Province, especially pay attention to the experience project scale.

In the comprehensive benefit, economic benefit and social benefit evaluation analysis, there are 3 sites in the low efficiency of the "excess" state. Therefore, we need to adjust from three aspects: The first, adjust the proportion of experience with other project investment, improve the investment efficiency to realize the scale development. The second, reduce travel element types, change the all-round outstanding tourism type characteristic to realize scale development. The third, dislocation development with the elements of leisure agriculture is the win-win competition. 
TAB.1 THE INDEX SYSTEM OF AGRICULTURAL EVALUATION

\begin{tabular}{|c|l|r|}
\hline \multicolumn{1}{|c|}{ First-level index } & \multicolumn{1}{|c|}{ Second-level index } & Third-level index \\
\hline \multirow{3}{*}{ Input indexes $(I)$} & Human $\left(I_{1}\right)$ & Scientific and Technological Employees \\
\cline { 2 - 3 } & Financial Resources $\left(I_{2}\right)$ & leisure experience investment \\
\cline { 2 - 3 } & Material Resources $\left(I_{3}\right)$ & Kinds of tourism fact in leisure agriculture \\
\hline \multirow{2}{*}{ Output indexes $(O)$} & Economic Benefit $\left(O_{1}\right)$ & annual revenues \\
\cline { 2 - 3 } & Social Benefit $\left(\mathrm{O}_{2}\right)$ & annual placement employment population \\
\hline
\end{tabular}

TAB.2 Data ANAlysis Results of Leisure Agriculture in HeBei ProvinCE BASED on DEA

\begin{tabular}{|c|c|c|c|c|c|c|c|c|}
\hline Parameter & $\operatorname{crste}(\theta)$ & vrste & scale & $S_{1}^{-}$ & $S_{2}^{-}$ & $S_{3}^{-}$ & $S_{1}^{+}$ & $S_{2}^{+}$ \\
\hline Qinhuangdao Jifa Co., Ltd. & 1.000 & 1.000 & 1.000 & 0.000 & 0.000 & 0.000 & 0.000 & 0.000 \\
\hline $\begin{array}{l}\text { Baoding long men shan } \\
\text { zhuang }\end{array}$ & 0.452 & 0.633 & 0.714 & 43.000 & 2200.000 & 2.000 & 0.000 & 666.220 \\
\hline $\begin{array}{l}\text { Tangshan fisherman Kiosk } \\
\text { leisure agricultural } \\
\text { sightseeing park }\end{array}$ & 1.000 & 1.000 & 1.000 & 0.000 & 0.000 & 0.000 & 0.000 & 0.000 \\
\hline $\begin{array}{l}\text { Shijiazhuang agricultural } \\
\text { Sightseeing Park }\end{array}$ & 0.554 & 1.000 & 0.554 & 0.000 & 0.000 & 0.000 & 0.000 & 0.000 \\
\hline $\begin{array}{l}\text { Xingtai blue sky eco-tourism } \\
\text { park }\end{array}$ & 1.000 & 1.000 & 1.000 & 0.000 & 0.000 & 0.000 & 0.000 & 0.000 \\
\hline $\begin{array}{l}\text { Langfang yongqing tianyuan } \\
\text { shanzhuang }\end{array}$ & 0.626 & 0.636 & 0.984 & 2.826 & 0.000 & 0.000 & 0.000 & 0.000 \\
\hline $\begin{array}{l}\text { Handan wenlan breeding Co., } \\
\text { Ltd. }\end{array}$ & 1.000 & 1.000 & 1.000 & 0.000 & 0.000 & 0.000 & 0.000 & 0.000 \\
\hline $\begin{array}{l}\text { Hengshui Deng Zhuang } \\
\text { agricultural technology } \\
\text { demonstration park }\end{array}$ & 1.000 & 1.000 & 1.000 & 0.000 & 0.000 & 0.000 & 0.000 & 0.000 \\
\hline $\begin{array}{l}\text { Chengde zhoutaizi modern } \\
\text { agricultural leisure park }\end{array}$ & 1.000 & 1.000 & 1.000 & 0.000 & 0.000 & 0.000 & 0.000 & 0.000 \\
\hline $\begin{array}{l}\text { Zhangjiakou wanquan xing } \\
\text { hua gou leisure ecological } \\
\text { Park }\end{array}$ & 0.482 & 1.000 & 0.482 & 0.000 & 0.000 & 0.000 & 0.000 & 0.000 \\
\hline
\end{tabular}

Note: $S_{1}^{-} 、 S_{2}^{-} 、 S_{3}^{-}$each represent input indicators, human, financial and material resources. $S_{1}^{+} 、 S_{2}^{+}$each represent the output variable economic and social benefits. crste: comprehensive technical efficiency, also known as the integrated efficiency. vrste: pure technical efficiency; scale: scale efficiency.

C. On the basis of building scientific and technological content, Operators need to improve management level and service quality.

Above 10 sites, there are 4 "excess" in inputs of scientific and technological employees. We need pay attention to improve the level of science and technology and the reasonable proportion of its matching management level and service quality, in order to achieve the best efficiency of input and output.
D. Operators are not only content to increase their economic benefits, but also pay attention to drive social benefits with local employment. It will make the leisure agriculture development rapidly and healthy.

For the low output in the above sites, we need to adjust the structure of corresponding input, in order to improve economic efficiency effectively. For the interests of the whole society, leisure agriculture parks will improve economic efficiency constantly. At the same time, we also needs to improve social benefits for recruiting local employment.

\section{ACKNOWLEDGMENT}

This paper is supported by the school of economics and management of the Hebei University of science and 
technology, and The 2013 International Conference on Education Technology and Management Science. The paper is one of the outcomes from the Soft Science Program of Hebei Province "The service platform generic technology research in the leisure agriculture of mountain" (subject No. 12237125D-4).

\section{REFERENCES}

[1] Jin-lu Li. Strategic thinking of the development in leisure agriculture and rural tourism in Hebei[N]. Hebei Daily, 2012, 7, 16 : the twelfth edition

[2] Yi Zhao. The international experience and its reality operating of the leisure agriculture. [J] Reform, 2011,07 : 96-100.
[3] He Sun,Fine Management of Institutions of Higher Learning, Master's thesis of Hebei University of Science and Technology , Shijiazhuang, 2008.

[4] Wei-Li Shi, Qing-Shu Kong, Chuan Sun.Analysis and Evaluation of Innovation Efficiency in the National Hi-Tech Zone Based on DEA [J]. Proceedings of 2010 International Conference on Machine Learning and Cybernetics, 2010, $07: 1332-1336$.

[5] Guoqing Yan, Qi Sun, Chao Chen, Hongsheng Zhong, Jianxiong Ren, "Research on the Evaluation Indicator System for Innovation Level in Chinese National Hi-tech Industrial Development Zone” , China Soft Science, pp. 141-148,Apr.2008. 